\title{
Craft Beers Fermented by Potential Probiotic Yeast or Lacticaseibacilli Strains Promote Antidepressant-Like Behavior in Swiss Webster Mice
}

\author{
Larissa Cardoso Silva ${ }^{1} \cdot$ Heitor de Souza Lago ${ }^{2} \cdot$ Márcia Oliveira Terra Rocha ${ }^{2} \cdot$ Vanessa Sales de Oliveira $^{3}$. \\ Roberto Laureano-Melo ${ }^{4}$ Evandro Toledo Gerhardt Stutz ${ }^{4}$ Breno Pereira de Paula ${ }^{2}$. \\ José Francisco Pereira Martins ${ }^{3} \cdot$ Rosa Helena Luchese $^{3} \cdot$ André Fioravante Guerra $^{2,5}$ [D $\cdot$ Paula Rodrigues ${ }^{1}$
}

Accepted: 25 December 2020 / Published online: 11 January 2021

๑) The Author(s), under exclusive licence to Springer Science+Business Media, LLC part of Springer Nature 2021

\begin{abstract}
This study aimed to produce a probiotic-containing functional wheat beer (PWB) by an axenic culture system with potential probiotic Saccharomyces cerevisiae var boulardii 17 and probiotic-containing functional sour beer (PSB) by a semi-separated co-cultivation system with potential probiotic Lacticaseibacillus paracasei DTA 81 and Saccharomyces cerevisiae S-04. Additionally, results obtained from in vivo behavioral tests with Swiss Webster mice treated with PWB or PSB were provided, which is scarce in the current literature. Although the use of $S$. boulardii to produce beers is not a novelty, this study demonstrated that $S$. boulardii 17 performance on sugar wort stills not completely elucidated; therefore, further studies should be considered before using the strain in industrial-scale production. Co-culture systems with lacticaseibacilli strain and S. cerevisiae have been reported in the literature for PSB production. However, lacticaseibacilli survivability in beer can be improved by semi-separated co-cultivation systems, highlighting the importance of growing lacticaseibacilli in the wort before yeast pitching. Besides, kettle hopping must be chosen as the method for hop addition to produce PSB. The dry-hopping method may prevent iso-alpha formation in the wort; however, a tendency to sediment can drag cells at the tank bottom and negatively affect $L$. paracasei DTA 81 viability. Despite stress factors from the matrices and the stressful conditions encountered during GI transit, potential probiotic S. boulardii 17 and potential probiotic L. paracasei DTA 81 withstood at sufficient doses to promote antidepressant effects in the mice group treated with PWB or PSB, respectively.
\end{abstract}

Keywords Brewery $\cdot$ Microbes $\cdot$ Beneficial $\cdot$ Host $\cdot$ Gut $\cdot$ Dysbiosis

André Fioravante Guerra

andrefioravanteguerra@gmail.com; andre.guerra@cefet-rj.br

1 Centro de Investigação de Montanha (CIMO), Instituto Politécnico de Bragança, Campus de Santa Apolónia, 5300-253 Bragança, Portugal

2 Centro Federal de Educação Tecnológica Celso Suckow da Fonseca (CEFET/RJ), Valença, Rio de Janeiro 27600 000, Brazil

3 Department of Food Technology, Federal Rural University of Rio de Janeiro, Seropédica, Rio de Janeiro 23.897 970, Brazil

4 Centro Universitário de Barra Mansa (UBM), Barra Mansa, Rio de Janeiro 27330-550, Brazil

5 Department of Food Engineering, Federal Center of Technological Education Celso Suckow da Fonseca, Valença, Rio de Janeiro 27600 000, Brazil

\section{Introduction}

Probiotics are extensively incorporated into food products to enhance consumer health. Considering the increasing popularity of producing craft beers, probiotic-containing functional beers represent a promising strategy to deliver probiotic strains by non-usual matrix. The term probiotic refers to live microorganisms that when administered in adequate amounts confer a health benefit on the host [1]. The frequent consumption of probiotics and/or prebiotics has a crucial role in the competitive exclusion of pathogens for restoring a healthy microbiota in the gut microbiome, combating dysbiosis in the gut microbial community, and preventing several correlated diseases [2,3].

Saccharomyces cerevisiae var. boulardii 17 (Merck, Beauvais, France) has been used to produce beers over the last 3 years [4-6]. Its metabolism to ferment beer wort is similar to conventional brewer's yeast. Besides, it presents 
tolerance to acid, ethanol, and gastrointestinal (GI) transit [7, 8]. S. boulardii 17 is indicated to health-impaired individuals since it plays a role in the maintenance and/or restoration of intestinal barrier function in many disorders [6]. Lacticaseibacilli strain may also be used to produce sour beer; this style of beer has an intentional acidity produced by microbial pathway or through the addition of fruit juice. Co-fermentation systems with lacticaseibacilli and Saccharomyces cerevisiae S-04 have been used for sour beer production as an alternative to the addition of acids [7]. However, the microbial competition may negatively affect the lacticaseibacilli viability indicating that another fermentation system should be studied. Semi-separated co-cultivation systems may be a proper alternative to provide competitive technological advances for lacticaseibacilli, improving its viability in fermentation with $S$. cerevisiae S-04.

L. paracasei DTA 81 is highlighted due to its safety and functional properties. Previous studies demonstrated its ability to inhibit Escherichia coli, Salmonella Typhimurium, Listeria innocua, and Candida albicans biofilms by competition, exclusion, and displacement mechanisms, either before or after GI transit. Additionally, the strain is $\gamma$-hemolytic (absent of $\beta$-hemolytic activity when grown on MRS agar containing $5 \%(w / v)$ sheep blood). L. paracasei DTA 81 also presented an ability to adhere to HT-29 cells, approximately ten times higher than the reference widespread probiotic commercial strain L. rhamnosus GG [8, 9]. L. paracasei DTA-81 easily assimilate glucose, showing restrictions to assimilate maltose [10]. Then, maltose can be used for the yeast inoculated later in the beer wort [11]. These characteristics were decisive when considering $L$. paracasei DTA 81 as a candidate to produce sour beer. Moreover, maternal supplementation (7.0 $\log$ cells per day) with $L$. paracasei DTA 83 , a very close genetic strain to the $L$. paracasei DTA 81 used in the present study [10], reduced the expression of GAD 65, GAD 67, and GABAA receptor $\alpha 3$ subunit in the hippocampus, modulating Swiss mice offspring [12].

In this context, the present study aimed to contribute to this field by (i) manufacturing functional beers and designing suitable fermentation systems for industrial-scale production, (ii) assessing microbial stress due to maturation and storage in matrices and after GI transit, and (iii) evaluating anxiolytic or anxiogenic-like activity in randomized controlled trials with Swiss Webster mice (light-dark box and tail-suspension behavior tests).

\section{Materials and Methods}

\section{Experimental Design}

Potential probiotic L. paracasei DTA 81 was isolated from stools of infants ( 1 to 3 weeks old) assisted by the
Human Milk Bank and the Neonatal Intensive Care Unit of Fernandes Figueira Institute (FIOCRUZ) located in the state of Rio de Janeiro, Brazil. It was identified by Gram staining, catalase reaction, and API $50 \mathrm{CH}$ tests (BioMerieux, Marcy-l'Etoile, France), as well as by sequencing the $16 \mathrm{~S}$ rDNA region $[9,10]$. Potential probiotic $S$. boulardii 17 was purchased at a local pharmacy (Valença, Rio de Janeiro, Brazil), as freeze-dried culture. S. cerevisiae S-04 dry ale yeast was purchased at a local market (Juiz de Fora, Minas Gerais, Brazil), also as a freeze-dried culture.

Two types of beer were produced with wort from the same mash: probiotic-containing functional wheat beer (PWB) and probiotic-containing functional sour beer (PSB). During the mash, samples were collected to measure the original gravity attenuation and the conversion rate of starch into sugar. The total volume of wort was divided into two portions and fermented separately to obtain PWB by an axenic cultivation system with potential probiotic $S$. boulardii 17 and PSB by a semi-separated co-cultivation system with potential probiotic $L$. paracasei DTA 81 and $S$. cerevisiae S-04. Samples were periodically taken for physical and microbiological analyses: six to eight sample collections during the fermentation, two collections per day during the maturation, and four collections during the storage period of 50 days. The anxiolytic or anxiogenic-like activity was assessed in randomized controlled in vivo trials with Swiss Webster mice (light-dark box and tail-suspension behavior tests). Water and pasteurized wheat beer, produced with a conventional brewer's yeast, were used as controls.

\section{Preparation of Beer Wort}

L. paracasei DTA 81 , stored at $-18{ }^{\circ} \mathrm{C}$, was thawed in a refrigerator $\left(4^{\circ} \mathrm{C}\right)$ for $6 \mathrm{~h}$ and activated by three successive overnight growth in deMan, Rogosa, and Sharp (MRS) broth medium (HiMedia, Mumbai, India). A flask with $1.5 \mathrm{~L}$ of unhopped wort was sterilized by autoclaving at $110^{\circ} \mathrm{C}$ for 10 min and inoculated with $1.0 \%(v / v)$ of $L$. paracase $i$ DTA 81 inoculum, followed by overnight incubation at $37^{\circ} \mathrm{C}$ to reach the minimum cell concentration at $c a .9 .0 \log$ colony forming unit $(\mathrm{cfu}) / \mathrm{mL}$. Freeze-dried S. boulardii 17 or S. cerevisiae S-04 pure cultures were rehydrated $(1.0 \%(w / v))$ in $1.5 \mathrm{~L}$ of unhopped wort at $20^{\circ} \mathrm{C}$, followed by incubation for $48 \mathrm{~h}$, until reaching the minimum cell concentration at $c a .8 .0 \log \mathrm{cfu} / \mathrm{mL}$.

Wort was prepared in a mash beer tank (D\&E Bier, Santa Luzia, Minas Gerais, Brazil) with a steam heating jacket and 300 $\mathrm{L}$ of nominal capacity, working fully. Wheat and barley malts were equi-reconstituted (8.3\%) into drinking water. Typical wheat beer ramp mash was conducted by successive steps of heating up $\left(1^{\circ} \mathrm{C} / \mathrm{min}\right)$ and time-outs, profiling $52,62,72$, and $78^{\circ} \mathrm{C}$ by $15,30,30$, and $10 \mathrm{~min}$, respectively. The heating was performed by circulating steam around the kettle $(15 \mathrm{bbl})$, which was provided by a wood-fired steam boiler. The total volume of 
wort was divided into two portions, each one containing $150 \mathrm{~L}$, aiming the production of PWB and PSB. Residues such as malt bark and denatured proteins were removed by sedimentation. Boiling with constant hand-mixing was performed for $60 \mathrm{~min}$ using a big spoon.

\section{PWB Production}

After 10 min of wort boiling, Hallertauer Mittelfrueh (BarthHaas Group ${ }^{\circledR}$, Nürnberg, Germany) hop pellets with $12.4 \%$ of alpha acids were added to the wort vessel at $4.2 \% \mathrm{w} / \mathrm{v}$, translating approximately 15 International Bittering Units (IBUs). Serpentine passage cooling system, with a $1.5 \mathrm{~m}$ linear length immersed into the wort vessel, was used for cooling the wort $\left(18^{\circ} \mathrm{C}\right)$. Drinking water at room temperature was used to top up the initial wort volume recovering the volume and the original gravity, which were affected by boiling. The fermentation process was carried out in a stainless conical beer fermentation tank designed with a torispherical and conical bottom. The temperature was controlled by circulating ethanol inside the cooling jackets. Potential probiotic $S$. boulardii 17 inoculum was pitched to obtain the final yeast concentration of $c a .6 .5 \log \mathrm{cfu} / \mathrm{mL}$. The wort was not aerated before pitching and the temperature was set at $18{ }^{\circ} \mathrm{C}$. After $36 \mathrm{~h}$ of fermentation, S. boulardii 17 unexpectedly stopped metabolizing sugars of the wort. In order to reactivate $S$. boulardii 17 performance, the temperature was suddenly increased to $25^{\circ} \mathrm{C}$ at a rate of $1{ }^{\circ} \mathrm{C} / \mathrm{h}$ and quickly reduced to $20^{\circ} \mathrm{C}$. Therefore, its metabolism was recovered, keeping on the consumption of substrate and the production of alcohol. After 5 days of fermentation, a natural tendency of original gravity attenuation was observed and PWB was cooled to approximately $0{ }^{\circ} \mathrm{C}$, followed by maturation during 2 weeks in the same fermentation tank.

\section{PSB Production}

After cooling the unhopped wort to $36{ }^{\circ} \mathrm{C}$ as previously described, it was inoculated with potential probiotic $L$. paracasei DTA 81 to reach the final concentration of $c a$. $7.0 \log \mathrm{cfu} / \mathrm{mL}$ and manually homogenized with a big spoon. After $30 \mathrm{~h}$ of $L$. paracasei DTA 81 growth, the wort temperature was reduced to $20^{\circ} \mathrm{C}$ at a rate of $2.7^{\circ} \mathrm{C} / \mathrm{h}$ and then inoculated with $S$. cerevisiae S-04 to reach the final yeast concentration of $c a$. $6.0 \log \mathrm{cfu} / \mathrm{mL}$. After 3 days of yeast fermentation, PSB was finally hopped. Kettle hopping or dry hopping methods were used to evaluate the bacteriostatic effect of hop on L. paracasei DTA 81 survivability. Kettle hopping was carried out by activating $2 \%(w / v)$ Warrior hop pellets (Barth-Haas Group ${ }^{\circledR}$, Yakima, Washington, USA) with $15.3 \%$ alpha acids in $200 \mathrm{~mL}$ of sterile deionized water at $95{ }^{\circ} \mathrm{C}$ for $10 \mathrm{~min}$, translating approximately 5 IBUs to the PSB. Dry hopping was performed by direct vat set adding $2 \%(w / v)$ Hallertau Magnum T-90 Baywa hop pellets with $12.4 \%$ alpha acids to PSB, translating about the same IBUs that the dry-hopping method. Since the original gravity was attenuated, PSB was cooled to approximately $0{ }^{\circ} \mathrm{C}$, followed by maturation during 2 weeks in the same fermentation tank.

\section{Microbial Enumeration}

L. paracasei DTA 81 was enumerated on MRS agar supplemented with $135 \mathrm{ppm}$ of natamycin (Merck, Darmstadt, Germany) to prevent the S. cerevisiae growth [7]. S. boulardii 17 was enumerated on the selective Wallerstein Laboratory (WL) agar medium (Oxoid, Basingstoke, UK) [13]. The drop-plate technique was applied for both lacticaseibacilli and yeast enumeration. A 12-well plastic microtiter plate was used to seed the drops $(25 \mu \mathrm{L})$. Before seeding, $1 \mathrm{~mL}$ of melted selective agar medium kept at $50{ }^{\circ} \mathrm{C}$ was added to the wells using a micropipette and sterile tips. After complete solidification, each dilution level was seeded in duplicate into two different wells of the plate. Each well of the plate was seeded with only one drop. Decimal dilutions (up to 8th level) were performed by serial aliquot transfers $(100 \mu \mathrm{L})$ to Eppendorf tubes containing $900 \mu \mathrm{L}$ of $0.1 \%$ sterile peptone water. Plates containing MRS or WL agar were incubated at 36 and $25^{\circ} \mathrm{C}$ for $48 \mathrm{~h}$, respectively. Colonies were counted using a manual colony counter (Interscience, Saint Nom, France), and the results were calculated using at least two successive dilution levels, according to Eq. 1 [14].

$N=\frac{\sum C}{V[n 1+0.1 n 2) d}$

where $\sum c$ is the sum of the colonies counted on the two plates retained from two successive dilutions (at least one of which contains a minimum of 10 colonies), $V$ is the volume of inoculum placed in each plate (mL), $n 1$ and $n 2$ are the number of plates selected in the first and second dilution, respectively, $d$ is the dilution corresponding to the first dilution retained.

\section{GI Tolerance Assay}

GI base juice was prepared $(0.11 \mathrm{~g} / \mathrm{L}$ of calcium chloride, $1.12 \mathrm{~g} / \mathrm{L}$ of potassium chloride, $2.0 \mathrm{~g} / \mathrm{L}$ of sodium chloride, and $0.4 \mathrm{~g} / \mathrm{L}$ of potassium dihydrogen phosphate) with distilled water and sterilized at $121{ }^{\circ} \mathrm{C}$ for $15 \mathrm{~min}$. Artificial gastric juice (GJ) was freshly prepared to a final volume of $75 \mathrm{~mL}$ by adding $3.5 \mathrm{~g} / \mathrm{L}$ of swine mucin and $0.26 \mathrm{~g} / \mathrm{L}$ of swine pepsin. The $\mathrm{pH}$ was adjusted to 2.0 with $1 \mathrm{M} \mathrm{HCl}$. An aliquot of beer $(1 \mathrm{~mL})$ was transferred into GJ and anaerobically incubated at $36^{\circ} \mathrm{C}$ for $45 \mathrm{~min}$, with moderate 
shaking. Subsequently, artificial intestinal juice was obtained to top up the final volume $(100 \mathrm{~mL})$ by adding $3.0 \mathrm{~g} / \mathrm{L}$ of bile salt, $1.95 \mathrm{~g} / \mathrm{L}$ of pancreatin, and $0.1 \mathrm{~g} / \mathrm{L}$ of egg white lysozyme to the GJ (all media from Sigma-Aldrich, St. Louis, Missouri, USA). The $\mathrm{pH}$ was adjusted to 7.0 with $1 \mathrm{M}$ sodium bicarbonate solution, followed by anaerobic incubation at $36^{\circ} \mathrm{C}$ for $180 \mathrm{~min}$, with moderate shaking [9]. The drop-plate technique was applied for microbial counts, as previously described.

\section{Alcohol, Glycerol, Acetic Acid, and pH Measurement}

The alcohol content by weight ( $\%$ ABW), by volume ( $\%$ $\mathrm{ABV})$, real extract (RE, $\left.{ }^{\circ} \mathrm{P}\right)$, and real degree of fermentation (\% RDF) of PWB and PSB were calculated by using the Balling's Eqs. (2-5) [15].

$$
\begin{aligned}
& \frac{A C(\% w / w)}{O E-A E}=b_{a 0}+\left(b_{a 1} \cdot O E\right) \\
& \frac{A C(\% w / w)}{O E-R E}=b_{b 0}+\left(b_{b 1} \cdot O E\right) \\
& A C(\% w / w)=\frac{A C(\% v / v) \cdot 0.7907}{S G} \\
& R D F(\%)=\left[\frac{100 \cdot(O E-R E)}{O E}\right] \cdot\left[\frac{1}{1-(0.005161 \cdot R E)}\right]
\end{aligned}
$$

where $b_{\mathrm{a} 0}, b_{\mathrm{a} 1}, b_{b 0}$, and $b_{b 1}$ are the statistical values corresponding to $0.372,0.00357,0.459$, and 0.00469 , respectively [15]; $O E$ - original extract $\left({ }^{\circ} \mathrm{P}\right) ; A E$ - apparent extract $\left({ }^{\circ} \mathrm{P}\right) ; S G$-specific gravity at $20^{\circ} \mathrm{C}$.

Glycerol and acetic acid were measured in PWB as indicators of sensory attributes related to the flavor of the beer. These compounds were measured by high-performance liquid chromatography (HPLC) system equipped with a binary pump (Varian Prostar 220), an injector (Rheodyne 7725i; Loop $20 \mu \mathrm{L}$ ), and an infrared detector (Varian RI-4). Data were analyzed using the Varian Chromatography Workstation software (version 4.5). The chromatographic separation was achieved using isocratic elution with a prepacked HPLC analysis column Aminex HPX-87H (Bio Rad; $300 \times 7.8$ mm, hydrogen form, $9 \mu \mathrm{m}$ particle size, $8 \%$ cross linkage, $\mathrm{pH}$ range 1-3) operating at $30{ }^{\circ} \mathrm{C}$ (JonesChromatography 7981 oven). The mobile phase consisted of an isocratic program of sulfuric acid $0.004 \mathrm{M}$, pumped at $0.6 \mathrm{~mL} / \mathrm{min}$ for a total run time of $30 \mathrm{~min}$. The injection volume was $20 \mu \mathrm{L}$.

Calibration curves, limit of detection (LOD), and limit of quantification (LOQ) were determined with five concentration levels of HPLC-grade standards of glycerol and acetic acid ranging from 0.1 to $8.0 \mathrm{mg} / \mathrm{mL}$. LOD and LOQ were calculated according to the following Eqs. 6 and 7 [16].

$L O D=3\left(\frac{s a}{b}\right)$

$L O Q=10\left(\frac{s a}{b}\right)$

where $s a$ is the standard deviation of the intercept of the regression line obtained from the calibration curve and $b$ is the slope of the line. The concentration was calculated as $\mathrm{g} / \mathrm{L}$, considering the dilution factors.

A portable $\mathrm{pH}$ meter (Akrom, São Leopoldo, Rio Grande do Sul, Brazil) with a digital microprocessor equipped with an automatic temperature compensation was used for $\mathrm{pH}$ measurements in PWB and PSB.

\section{In Vivo Trials for Beneficial Effect Assessment}

Light-dark box and tail suspension test were performed to study anxiety-like and depression-like behavior in mice [17, 18]. Swiss Webster mice (25 days old; around $30 \mathrm{~g}$ ) from the colony of the University of Barra Mansa (UBM), located in the state of Rio de Janeiro, Brazil, were used in this protocol. The mice were housed in plastic cages $(35 \times 50 \times 20 \mathrm{~cm})$ and randomly allocated into three groups $(N=8)$. Each group was daily treated with PWB or PSB $(100 \mu \mathrm{L})$ for 7 days. Sterile distilled water and pasteurized wheat beer (Mascates, Valença, Rio de Janeiro, Brazil) were used as negative control and blank, respectively. The beer was fermented by a conventional wheat beer yeast (Lallemand, Vienna, Austria) using the same production parameters applied to obtain PWB. All animals were maintained under the following conditions: controlled temperature $\left(20 \pm 2{ }^{\circ} \mathrm{C}\right)$, exposure to a $12 \mathrm{~h} / 12 \mathrm{~h} \mathrm{light/dark} \mathrm{cycle,} \mathrm{free} \mathrm{access} \mathrm{to} \mathrm{drinking} \mathrm{water,}$ and standard rodent chow.

During 7 continuous days, light-dark box and tailsuspension tests were conducted with the animals. In the light-dark box test, the animals were placed individually in an acrylic cage $(450 \times 270 \times 270 \mathrm{~mm}-$ length/height/ width). The cage was divided into two sections: one was $2 / 3$ illuminated (400 lx), and the remaining section was closed and maintained in the dark. The sections were connected through a small opening $(80 \mathrm{~mm}$ of width and $120 \mathrm{~mm}$ of length) located in the center of the divisor wall. Mice were placed into the dark side and could move freely from one chamber to another for $5 \mathrm{~min}$. The time spent on the illuminated side, the number of transitions, and the latency when the animal got on the light side for the first time were recorded during this period. In the tail suspension test, the mice were suspended $10 \mathrm{~cm}$ above the stand by an adhesive tape placed approximately $1 \mathrm{~cm}$ from the tip of the tail. The test was recorded for $5 \mathrm{~min}$. Time of immobility and latency, 
at the first immobilization episode, were determined during this period.

The tests were performed with an interval of 1 day beginning by the light-dark box test, abiding by progressive invasiveness degree. Behavioral tests were executed between 7 and 10 a.m. During each test, the experimenter remained outside the testing room, except between trials. Each test was recorded and behavior parameters were analyzed by at least two observers.

This investigation was carried out according to the Guide for the Care and Use of Laboratory Animals published by the US National Institutes of Health (NIH Publication No. 85-23, revised in 1996). In addition, it was approved by the Institutional Animal Welfare Committee in accordance with the pertinent Brazilian legislation, under protocol number $001 / 2020$

\section{Statistical Analysis}

All results were presented as means \pm standard deviation. The assumption of normal data distribution was assessed with the Shapiro-Wilk test. Grubbs and Tietjen-Moore tests were used to detect single or multiple outliers. Prism 5 statistical software (GraphPad, San Diego, California, USA) was applied to evaluate the behavior analyses. Significant differences in the microbial survivability analyses were evaluated by analysis of variance (ANOVA), followed by Fisher's (LSD) test using the XLSTAT software (2019) (Addinsoft, Boston, Massachusetts, USA). Results were statistically significant when $p \leq 0.05$.

\section{Results}

The potential probiotic S. boulardii 17 growth phase (log) observed during PWB production started suddenly after pitching the wort, excluding the adaptation (lag) and growth acceleration phases. The stationary phase started $36 \mathrm{~h}$ after pitching. Slight reductions in original gravity, $\mathrm{pH}$, and alcohol production were simultaneously determined (Fig. 1). Therefore, at the end of the fermentation process, the following values were found: final gravity $\left({ }^{\circ} \mathrm{P}\right)=4.5$, $\% \mathrm{ABV}=4.26$, and final concentration of live $S$. boulardii

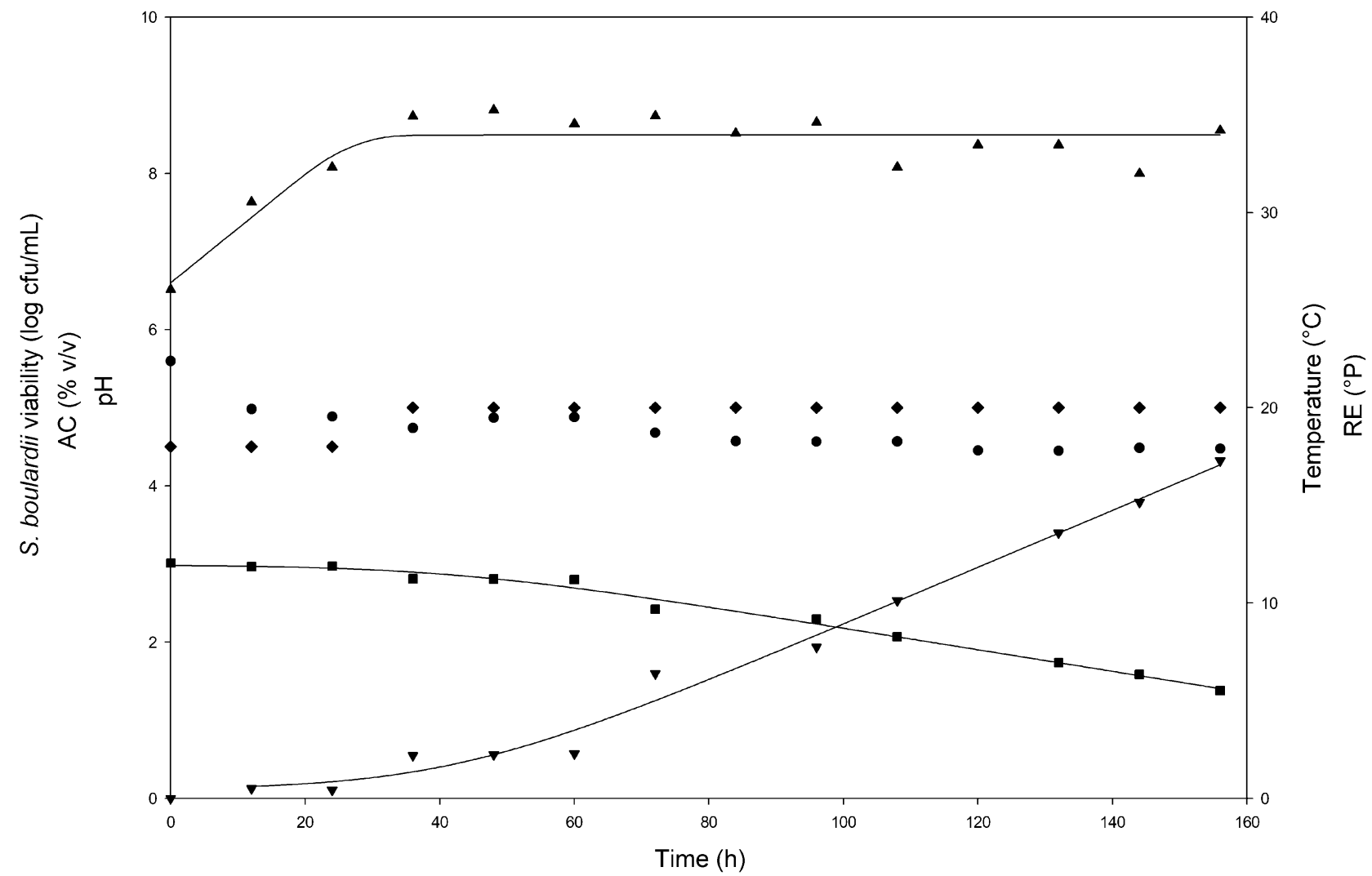

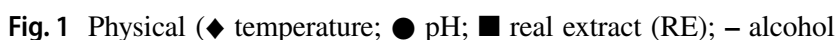
by volume $(\mathrm{ABV}))$ and microbiological $(\boldsymbol{\Lambda} S$. boulardii 17$)$ viability during probiotic-containing functional wheat beer (PWB) production. Baranyi's mathematical model was applied to model microbial viability, $\mathrm{RE}$, and $\mathrm{ABV}$, using DMFit software, version 3.5 (Institute of Food Research, Norwich, UK). PWB was produced by an axenic culture system with potential probiotic $S$. boulardii 17 . SigmaPlot 12.0 (Systat, San Jose, California, USA) was used to create the graphic 
Table 1 Kinetic parameters obtained during the production of probiotic-containing functional sour beer (PSB) and probiotic-containing functional wheat beer (PWB)

\begin{tabular}{|c|c|c|c|}
\hline \multirow[t]{2}{*}{ Parameters } & \multicolumn{2}{|l|}{ PSB } & \multirow[b]{2}{*}{ PWB } \\
\hline & DTA 81 & S-04 & \\
\hline$X_{0}(\log$ cell $/ \mathrm{mL})$ & 7.14 & 7.95 & 6.60 \\
\hline$X_{\max }(\log$ cell $/ \mathrm{mL})$ & 9.45 & & 8.49 \\
\hline$X_{\text {res }}(\log$ cell $/ \mathrm{mL})$ & & 7.38 & \\
\hline$\lambda(\mathrm{h})$ & 14.29 & & 0.00 \\
\hline SL (h) & & 12.91 & \\
\hline$\mu_{\max }\left(\mathrm{h}^{-1}\right)$ & 0.94 & & 0.07 \\
\hline$k_{\max }\left(\mathrm{h}^{-1}\right)$ & & -0.01 & \\
\hline$R^{2}$ & 0.9637 & 0.9614 & 0.8063 \\
\hline SE & 0.2220 & 0.0390 & 0.2674 \\
\hline$Y_{\mathrm{X} / \mathrm{S}}($ cell/g of extract consumed $)$ & $8.61 \times 10^{11}$ & $-1.07 \times 10^{9}$ & $4.53 \times 10^{9}$ \\
\hline$Y_{\mathrm{P} / \mathrm{X}}(\mathrm{g}$ of alcohol produced/cell $)$ & & $-5.93 \times 10^{-11}$ & $1.36 \times 10^{-11}$ \\
\hline $\begin{array}{l}Y_{\mathrm{P} / \mathrm{S}}(\mathrm{g} \text { of alcohol produced/g of extract } \\
\text { consumed })\end{array}$ & & 0.06 & 0.06 \\
\hline$\mu_{\mathrm{S}}(\mathrm{g}$ of extract consumed/cell/h) & $1.09 \times 10^{-12}$ & $1.15 \times 10^{-11}$ & $1.54 \times 10^{-11}$ \\
\hline$\mu_{\mathrm{P}}(\mathrm{g}$ of alcohol produced/cell/h) & & $7.33 \times 10^{-13}$ & $9.48 \times 10^{-13}$ \\
\hline
\end{tabular}

$X_{0}$ initial yeast or lacticaseibacilli concentration, $X_{\text {máx }}$ maximum yeast or lacticaseibacilli concentration, $X_{\text {res }}$ residual yeast concentration, $\lambda$ lag phase period, $S L$ shoulder length time, $\mu_{\text {máx }}$ specific maximum growth rate, $k_{\text {máx }}$ maximum specific inactivation rate, $R^{2}$ coefficient of determination, $S E$ standard error, $Y_{X / S}$ yield factor of substrate to cell conversion, $Y_{P / X}$ yield factor of cell to alcohol conversion, $Y_{P / S}$ yield factor of substrate to alcohol conversion, $\mu_{S}$ specific substrate consumption rate, $\mu_{P}$ specific alcohol production rate

PSB was produced by a semi-separated co-cultivation system with potential probiotic $L$. paracasei DTA 81 and $S$. cerevisiae S-04. PWB was produced by an axenic culture system with potential probiotic $S$. boulardii 17 $17(\log \mathrm{cfu} / \mathrm{mL})=8.46($ Fig. 1 and Table 1$)$. During wort fermentation by $S$. boulardii 17 , the production of acetic acid was higher (about 6 times) than the sensory limit related to the beer taste, according to Zhang et al. [19]. Glycerol production was below the threshold of perception, as described by Zhao et al. [20] (Table 2).

Table 2 Calibration parameters of instrumentation for acid acetic (AA) and glycerol (Gly) quantification in probiotic-containing functional wheat beer (PWB)

\begin{tabular}{lll}
\hline Standard & AA & Gly \\
\hline Concentration $(\mathrm{g} / \mathrm{L})$ & $1.293 \pm 0.023$ & $0.425 \pm 0.138$ \\
$R_{\mathrm{t}}$ (retention time) & 27.30 & 24.23 \\
Calibration curve & $\mathrm{y}=823$ & $\mathrm{y}=1540$ \\
& $882.7879 \mathrm{x}-2$ & $393.1498 \mathrm{x}-4$ \\
& 984.6326 & 300.1674 \\
Correlation coefficient $\left(r^{2}\right)$ & 1.0000 & 1.0000 \\
Linearity range $(\mathrm{ng} / \mathrm{mL})$ & $0.0-2.0$ & $0.0-2.0$ \\
LOD $(\mathrm{g} / \mathrm{L})$ & 0.01 & 0.01 \\
LOQ $(\mathrm{g} / \mathrm{L})$ & 0.04 & 0.03 \\
\hline
\end{tabular}

PWB was produced by an axenic culture system with potential probiotic S. boulardii 17

$L O D$ limit of detection of the chromatographic method, $L O Q$ limit of quantification of the chromatographic method
In the PSB production, the potential probiotic L. paracase DTA 81 lag phase occurred within $6 \mathrm{~h}$ after wort pitching. The $\log$ phase started after $6 \mathrm{~h}$ and extended up to $22 \mathrm{~h}$ of process, presenting a concentration of $9.45 \mathrm{log} \mathrm{cfu} / \mathrm{mL}$. L. paracasei DTA 81 growth greatly affected the wort acidification and the original gravity value. $\mathrm{pH}$ values ranged from 5.71 to 3.30 , while a slight increase in the original gravity value was determined. $\mathrm{pH}$ values remained almost constant at 3.10 with the $S$. cerevisiae S-04 inoculation (after $30 \mathrm{~h}$, temperature $=20^{\circ} \mathrm{C}$ ). However, changes in original gravity values and alcohol levels were noticed, showing a gradual reduction of original gravity and the production of alcohol (Fig. 2 and Table 1).

L. paracasei DTA 81 and S. boulardii 17 population did not show significant reductions over 20 days of storage at $0{ }^{\circ} \mathrm{C}$, remaining above $8.0 \log \mathrm{cfu} / \mathrm{mL}$. The considerable overlap of stress factors during storage time and GI transit significantly affected the microbial survivability $(p \leq 0.05)$. $L$. paracasei DTA 81 population in PSB was reduced in a range of $0.5 \log \mathrm{cfu} / \mathrm{mL}$ when the dry hopping method was applied, as shown in Table 3.

Figure 3 presents the evaluation of the depression and anxiety-like behavior in mice treated with PSB and PWB, respectively. Whereas PSB demonstrated a great potential to reduce the immobility time, PWB increased the latency during the first immobility episode in the tail-suspension 


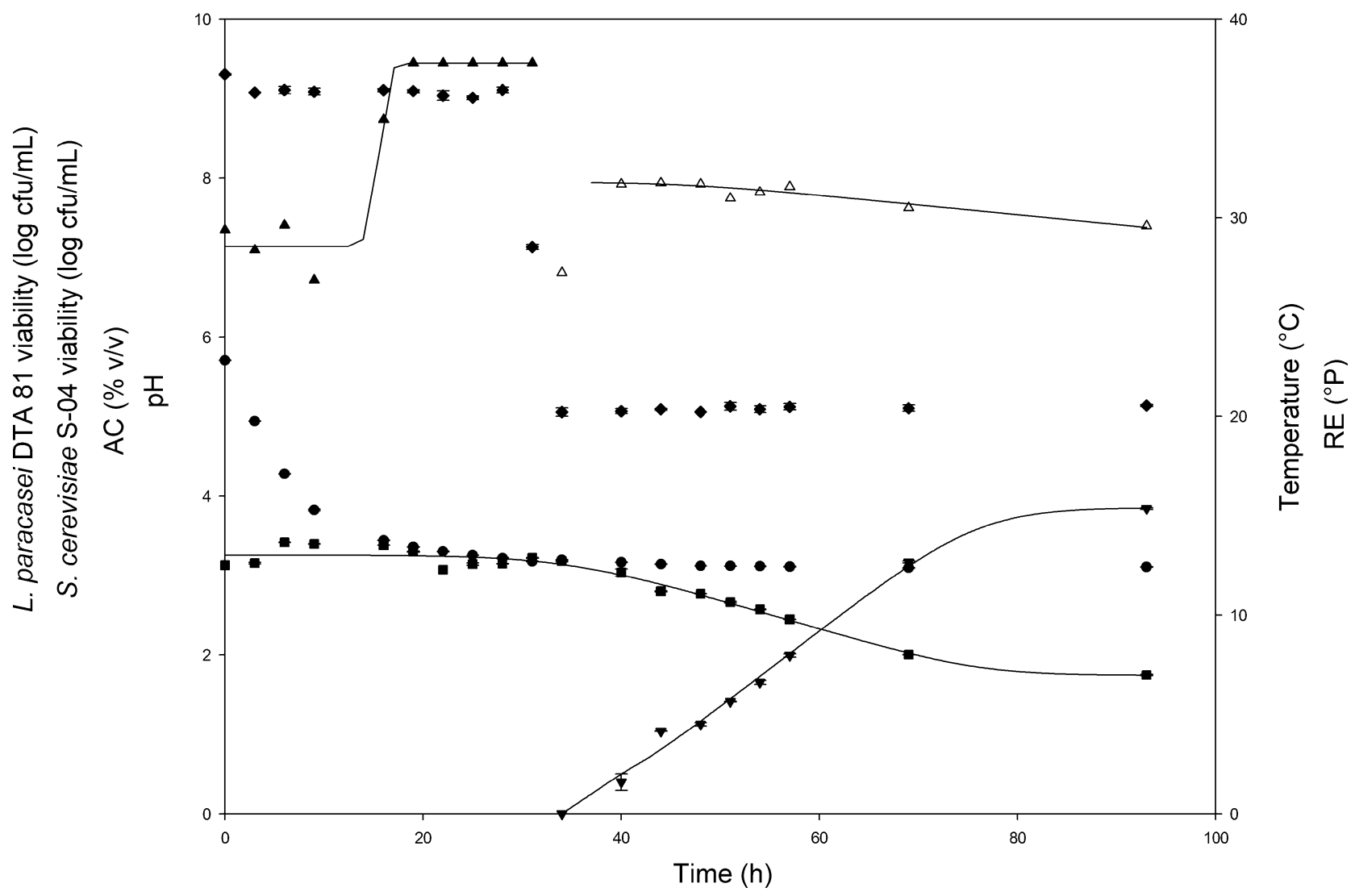

Fig. 2 Physical ( temperature; $\mathbf{p H}$; real extract (RE); - alcohol by volume $(\mathrm{ABV})$ ) and microbiological ( $\boldsymbol{\Lambda}$ L. paracasei DTA 81 ; S. cerevisiae S-04) viability during probiotic-containing functional sour beer (PSB) production. Baranyi's mathematical model was applied to model microbial viability, RE, and ABV, using DMFit software, version 3.5 (Institute of Food Research, Norwich, UK). PSB was produced by a semi-separated co-cultivation system with potential probiotic $L$. paracasei DTA 81 and S. cerevisiae S-04. SigmaPlot 12.0 (Systat, San Jose, California, USA) was used to create the graphic
Table 3 Viability of S. boulardii 17 and L. paracasei DTA 81 and microbial stress originated from hopping and gastric $(\mathrm{G})$ and gastrointestinal (GI) transit in probiotic-containing functional sour beer
(PSB) and probiotic-containing functional wheat beer (PWB) $(n=3$, mean \pm standard deviation)

\begin{tabular}{|c|c|c|c|c|c|c|c|c|c|}
\hline \multirow[b]{3}{*}{ Time (days) } & \multicolumn{9}{|c|}{ Microbial viability (log cfu/mL) } \\
\hline & \multicolumn{3}{|c|}{ Kettle hopping } & \multicolumn{3}{|l|}{ Dry hopping } & \multirow[b]{2}{*}{ PWB } & \multirow[b]{2}{*}{$\begin{array}{l}\mathrm{PWB}(\mathrm{G} \\
\text { transit) }\end{array}$} & \multirow[b]{2}{*}{$\begin{array}{l}\text { PWB (GI } \\
\text { transit) }\end{array}$} \\
\hline & PSB & $\begin{array}{l}\text { PSB (G } \\
\text { transit) }\end{array}$ & $\begin{array}{l}\text { PSB (GI } \\
\text { transit) }\end{array}$ & PSB & $\begin{array}{l}\text { PSB (G } \\
\text { transit) }\end{array}$ & $\begin{array}{l}\text { PSB (GI } \\
\text { transit) }\end{array}$ & & & \\
\hline 0 & $\begin{array}{l}9.45 \pm 0.00 \\
\mathrm{a}\end{array}$ & $\begin{array}{l}8.88 \pm 0.02 \\
\text { bcd }\end{array}$ & $8.78 \pm 0.03 \mathrm{~d}$ & $8.98 \pm 0.01 b$ & $\begin{array}{l}8.92 \pm 0.08 \\
b c\end{array}$ & $8.84 \pm 0.03 \mathrm{~cd}$ & $\begin{array}{l}8.94 \pm 0.01 \\
a\end{array}$ & $8.94 \pm 0.01 \mathrm{a}$ & $8.91 \pm 0.00 \mathrm{a}$ \\
\hline 10 & $\begin{array}{l}9.42 \pm 0.04 \\
\mathrm{a}\end{array}$ & $\begin{array}{l}8.91 \pm 0.06 \\
\mathrm{a}\end{array}$ & $8.17 \pm 1.14 \mathrm{a}$ & $8.94 \pm 0.03 \mathrm{a}$ & $\begin{array}{l}8.86 \pm 0.00 \\
\mathrm{a}\end{array}$ & $8.69 \pm 0.06 \mathrm{a}$ & $\begin{array}{l}8.89 \pm 0.08 \\
\mathrm{a}\end{array}$ & $8.85 \pm 0.12 \mathrm{a}$ & $8.86 \pm 0.09 \mathrm{a}$ \\
\hline 20 & $\begin{array}{l}9.36 \pm 0.05 \\
\mathrm{a}\end{array}$ & $\begin{array}{l}8.84 \pm 0.05 \\
\text { bc }\end{array}$ & $8.75 \pm 0.01 \mathrm{c}$ & $8.96 \pm 0.04 b$ & $\begin{array}{l}8.84 \pm 0.11 \\
b c\end{array}$ & $8.44 \pm 0.12 \mathrm{~d}$ & $\begin{array}{l}8.53 \pm 0.57 \\
\mathrm{a}\end{array}$ & $8.55 \pm 0.42 \mathrm{a}$ & $8.55 \pm 0.37 \mathrm{a}$ \\
\hline 50 & $\begin{array}{l}8.50 \pm 0.64 \\
\mathrm{a} *\end{array}$ & $\begin{array}{l}7.73 \pm 0.91 \\
b *\end{array}$ & $\begin{array}{l}7.75 \pm 0.17 \\
b *\end{array}$ & $\begin{array}{l}7.46 \pm 0.12 \\
b c *\end{array}$ & $\begin{array}{l}6.09 \pm 0.45 \\
\mathrm{c} *\end{array}$ & $5.23 \pm 0.17 \mathrm{~d} *$ & $\begin{array}{l}8.39 \pm 0.26 \\
\text { a }\end{array}$ & $\begin{array}{l}8.03 \pm 0.21 \\
b *\end{array}$ & $\begin{array}{l}8.00 \pm 0.29 \\
b *\end{array}$ \\
\hline
\end{tabular}

Different lowercase letters (row) at the same time (days) and to the same microorganism indicate significant differences among groups by Fisher's (LSD) test $(p \leq 0.05)$. Asterisks in the same column indicate significant differences for the same treatment by Dunnett's test $(p \leq 0.05) —$ day 0 was used as control. PSB was produced by a semi-separated co-cultivation system with potential probiotic L. paracasei DTA 81 and $S$. cerevisiae S-04. PWB was produced by an axenic culture system with potential probiotic S. boulardii 17 
a

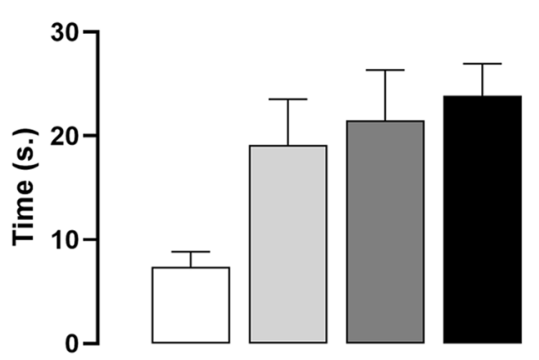

Time in Light Side

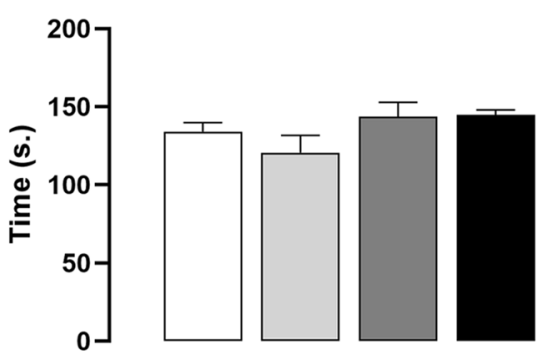

Transitions

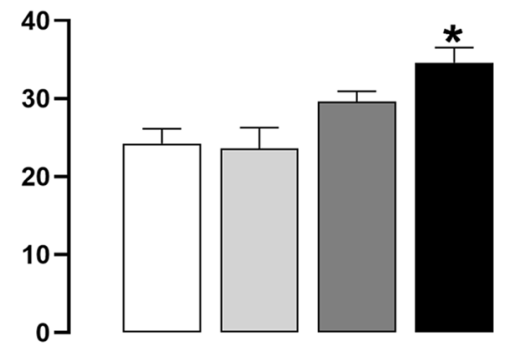

b

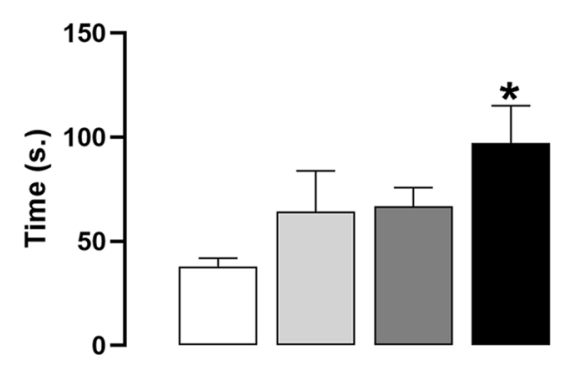

Fig. 3 Evaluation of exploratory activity and anxiety-like behavior in mice treated with probiotic-containing functional wheat beer (PWB) ( ) or probiotic-containing functional sour beer (PSB) ( ), pasteurized wheat beer ( $\square$ ) or drinking water as control ( ) through the open field (a) and tail suspension (b) tests. In this protocol, PWB and PSB stored for 4 weeks at $0{ }^{\circ} \mathrm{C}$ were used. Microbial daily dose above $7 \log$ cell/animal was assured during the 7 days of

test. This event was not statistically significant in the mice group treated with pasteurized wheat beer fermented by a conventional brewer yeast. In the light-dark box test, a greater number of transitions across the light and dark sides of the cage was noticed in the mice group treated with PWB.

\section{Discussion}

The ability of $S$. boulardii to act as a brewer yeast for the production of functional beer was previously demonstrated [5, 11, 21-23]. By evaluating the S. boulardii 17 metabolism during fermentation in this study, it was possible to determine its decline after 2 days of fermentation at $18{ }^{\circ} \mathrm{C}$. To re-activate the $S$. boulardii 17 metabolism, the wort temperature was increased to $25^{\circ} \mathrm{C}$ (about $1{ }^{\circ} \mathrm{C} / \mathrm{min}$ ) and immediately reduced to $20^{\circ} \mathrm{C}$. Therefore, the fermentation was carried out at $20^{\circ} \mathrm{C}$. This event indicates the role of the temperature on the proper metabolism of $S$. boulardii 17 on the sugar wort (Online Source 1, Supplementary Material). The preference of $S$. boulardii 17 by glucose before all other sugars has been reported in the literature. Wort sugars, such as maltose, are only consumed once glucose is scarce, about $40 \mathrm{~h}$ of fermentation. Most studies using S. boulardii as brewer yeast describe the fermentation process at $36{ }^{\circ} \mathrm{C}$;

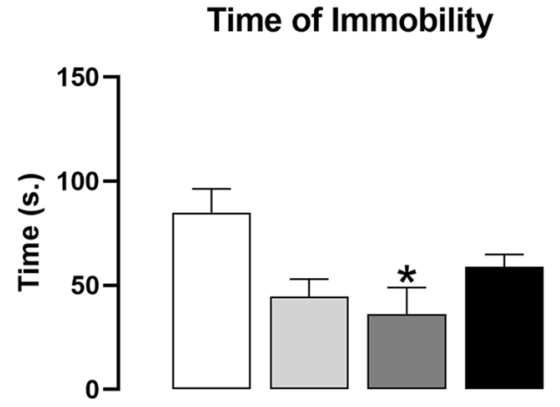

intervention $(100 \mu \mathrm{L} /$ gavage $) .{ }^{*} p \leq 0.05 . N=8$ mice per group. PSB was produced by a semi-separated co-cultivation system with potential probiotic L. paracasei DTA 81 and S. cerevisiae S-04; PWB was produced by an axenic culture system with potential probiotic $S$. boulardii 17. Prism 5 (GraphPad, San Diego, California, USA) was used to create the graphic

therefore, they do not show the importance of applying different temperatures to optimize $S$. boulardii metabolism. In addition, undesirable secondary compounds such as acetic acid and glycerol may be produced at $36^{\circ} \mathrm{C}$ [5].

Acetic acid production by brewer's yeasts is related to cellular stress, especially when there is a shortage of nutrients. When evaluating S. boulardii 17 metabolism in a medium with glucose and without maltose, Paula et al. [5] observed that all glucose was consumed and the acetic acid production substantially increased by the end of the exponential growth phase (about $40 \mathrm{~h}$, at $36^{\circ} \mathrm{C}$ ). Thus, proper temperature profile during the wort fermentation may reduce aftertaste resulting from the production of acetic acid by stressed $S$. boulardii 17 cells. This fact demonstrates that the strain must be carefully used in brewing processes since acetic acid is an undesirable compound that compromises the taste of beers.

On the contrary, sour beer has an intentionally acidic, tart, or sour taste, which can be produced during maturation or added during the process to confer unique products [24]. Studies aiming to attend the demand for faster sour beer production are of great importance and highlight diverse techniques to reduce the time of fermentation. Co-fermentation systems with lacticaseibacilli and brewer yeast seem to be suitable alternatives to the addition of acids [25]. For PSB production, potential probiotic L. paracasei 
DTA 81 grew axenically in wort, showing an increase of original gravity values due to higher density of the lactic acid $(1.206 \mathrm{~g} / \mathrm{mL})$ compared with the beer wort [26, 27]. $S$. cerevisiae S-04 was able to produce alcohol in the soured wort after $L$. paracasei DTA 81 growth (Fig. 2).

Functional beers can be produced either by fermentation with potential probiotic yeast or potential probiotic lacticaseibacilli strains. Since potential probiotics are commonly incorporated into food to improve gut balance, they must present beneficial effects and maintain their functionality in loco. In beer production, potential probiotic microorganisms are exposed to stressful conditions over the fermentation process such as the formation of alcohol and acids. Besides, they are also stressed during the GI transit due to the presence of acids, digestive enzymes, hydrogen peroxide, lysozyme, and others [28]. In the present study, microbial survivability in PWB and PSB was reduced during the storage time (50 days), mainly after GI transit. Moreover, the dry-hopping method applied in the PSB production greatly affected $L$. paracase $i$ DTA 81 survivability.

The kettle hopping method releases alpha acids that are converted into iso-alpha acids during boiling. Consequently, it imparts the characteristic bitter taste of beer and provides a bacteriostatic effect, especially on Gram-positive bacteria. The prenyl group affects the functions of the microbial plasmatic membrane, which may also represent a barrier to potential probiotic strain viability when a living microorganism at a suitable dose is linked to benefits on consumer health [29]. On the contrary, the dry-hopping method does not have a boiling step and may avoid the presence of iso-alpha acids, preserving the microbial viability. However, a tendency to sediment can drag cells at the tank bottom. This method negatively affected potential probiotic $L$. paracasei DTA 81 survivability in PSB (Table 1), highlighting that it must be used with caution for PSB production.

Regarding the behavioral tests performed with mice, PWB was able to reduce the aversion of rodents to illuminated areas. This fact was demonstrated by the spontaneous exploratory behavior of rodents in response to moderated stress like new environment and light. The light-dark test may be useful to predict anxiety-like activity in mice. The literature has reported that the number of transitions is an index of activity-exploration, considering the animal habituation over time. Besides, the time spent in each compartment may reflect the animal aversion to light [30]. In mice treated with PSB, the results obtained for the latency time and the number of transitions did not present significant differences in comparison with the other treatments $(p \leq 0.05)$ (Fig. 3a).

The results obtained in the tail-suspension test indicated that PWB or PSB may provide an antidepressant behavior avoiding major depressive disorder in mice (Fig. 3a). According to this test, immobility is a behavior that is pharmacologically related to depression since anti-depressant drugs increase latency to immobility and reduce immobility time. The alternation between movement and passivity represents an adaptive parameter, as an individual exposed to an aversive situation without a solution can choose two behavior patterns: seek a solution through intense motor activity and consequent energy expenditure or wait for a solution, standing still and saving energy [31]. Major depressive disorders are debilitating disease characterized by depressed mood, lack of interest, impaired cognitive function, and vegetative symptoms, such as disturbed sleep or appetite [32]. Lack of information on the etiology of major depressive disorders leads to inadequate treatments, resulting in the abusive use of drugs that cause various side effects.

Probiotic microorganisms are fundamental in combating depression [33]. Links between the central nervous system and gut microbiota have drawn the researcher's attention, being the focus of several studies. The gut microbiota has the potential to produce or stimulate the production of neurotransmitters and neuroactive compounds, such as serotonin, GABA, and dopamine, which can modulate bacterial growth [34].

In this context, a recent study demonstrated that oral gavage of either live or heat-killed $L$. paracase i is capable of reducing the depression-like behavior induced by chronic administration of corticosterone in mice. Interestingly, the therapeutic efficacy of this probiotic strain was equivalent or even more effective than fluoxetine, one of the most used drugs for the treatment of major depression disorders. Additionally, this study demonstrated that these effects seem to be mediated by increased levels of serotonin and brain-derived neurotrophic factor in the brain [31]. Moreover, L. paracasei also increases the levels of short chain fatty acids. Among them, acetate and butyrate can be highlighted [32]. The latter has been reported for its antidepressant and neuroprotective actions in animal models of chronic stress and depression. These actions are also related to high concentration of serotonin in brain and brain-derived neurotrophic factor expression [33, 34]. Thereby, as evidence show that brain-derived neurotrophic factor is critically decreased in mood disorders and plays an essential role in most anti-depressant treatments [35], PWB or PSB may probably induce antidepressant effects by increasing short chain fatty acids, which can positively modulate serotonin-brain-derived neurotrophic factor system. However, further studies must be conducted to evaluate the substances produced during the potential probiotic-induced fermentative processes of strains and their possible psychobiotic properties.

Indeed, probiotic-containing foods have shown decisive effects on lowering the risk for self-reported diagnosis of clinical depression. Additionally, they have the potential to improve brain function in humans through gut-brain axis [36]. The diversity of gut microbiomes has been strongly linked to mood-related behaviors, including major depressive 
disorder, since there is a bi-directional communication system among microbiome-gut-brain axis mediated by neuroimmune, neuroendocrine, and sensory neural pathways [37]. Current studies suggest that probiotic strains may exert positive effects on panic, anxiety, neurophysiological anxiety, negative affect, worry, and mood regulation. Moreover, this is an event related to a strain-dependent trait and varies considerably among strains within the same species [38]. Therefore, starter cultures must be carefully selected.

\section{Conclusion}

Despite stress factors from the matrices and the stressful conditions encountered during GI transit, potential probiotic $S$. boulardii 17 and potential probiotic $L$. paracasei DTA 81 strains withstood at sufficient doses to promote antidepressant effects in the mice group treated with PWB or PSB, respectively. Thus, the present study showed such enthusiastic results regarding the potential of probiotic-containing functional beers to enhance the welfare of consumers, encouraging further studies to investigate the mechanisms of the matrices in the bidirectional communication between gut-brain axis.

Although the consumption of beers produced by an axenic culture system with potential probiotic $S$. boulardii 17 may provide beneficial effects to consumers, S. boulardii 17 metabolism on sugar wort stills not completely elucidated. Therefore, studies must be carried out to optimize the fermentation parameters before using the strain in industrialscale production. Additionally, cellular stress during the process may cause an aftertaste in the beer, resulting from the production of acetic acid.

Author Contributions Larissa Cardoso $\mathrm{Silva}^{1}$ carried out the chromatography measurements. Heitor de Souza Lago ${ }^{2}$, Márcia Oliveira Terra Rocha ${ }^{2}$, and Breno Pereira de Paula ${ }^{2}$ manufactured the experimental batches of the functional beers. Roberto Laureano-Melo ${ }^{4}$ and Evandro Stutz $^{4}$ carried out in vivo trials for beneficial effect assessment in mice. Vanessa Sales de Oliveira ${ }^{3}$ drafted and designed the manuscript with support from André Fioravante Guerra ${ }^{2 *}$. José Pereira Francisco Martins ${ }^{3}$ and Rosa Helena Luchese ${ }^{3}$ contributed to the design and implementation of the research, analysis of the results, and manuscript writing. André Fioravante Guerra ${ }^{2 *}$ and Paula Cristina Azevedo Rodrigues ${ }^{1}$ developed the project and main conceptual ideas and were in charge of overall direction and planning. All authors provided critical feedback and helped organized the research, analysis, and manuscript.

Funding The Foundation for Science and Technology (FCT, Portugal) provided financial support by national funds FCT/MCTES to CIMO (UIDB/00690/2020) and the Brazilian National Council for Scientific and Technological Development (CNPq).

Data Availability All data generated or analyzed during this study are included in this published article and its supplementary information files.

\section{Compliance with Ethical Standards}

Conflict of Interest The authors declare that they have no conflict of interest.

\section{References}

1. FAO, WHO (2002) Guidelines for the evaluation of probiotics in food. Ontario, London

2. Wilkins LJ, Monga M, Miller AW (2019) Defining dysbiosis for a cluster of chronic diseases. Sci Rep 9:12918. https://doi. org/10.1038/s41598-019-49452-y

3. Terpou A, Papadaki A, Lappa IK et al (2019) Probiotics in food systems: significance and emerging strategies towards improved viability and delivery of enhanced beneficial value. Nutrients 11:1591. https://doi.org/10.3390/nu11071591

4. Senkarcinova B, Dias I, Nešpor J, Brányik T (2018) Probiotic alcoholfree beer made with Saccharomyces cerevisiae var. boulardii. LWT 100:362-367. https://doi.org/10.1016/j.lwt.2018.10.082

5. Paula BP, Chávez DWH, Lemos Junior WJF et al (2019) Growth parameters and survivability of Saccharomyces boulardii for probiotic alcoholic beverages development. Front Microbiol 10:2092. https://doi.org/10.3389/fmicb.2019.02092

6. Pais P, Almeida V, Y1lmaz M, Teixeira MC (2020) Saccharomyces boulardii: what makes it tick as successful probiotic? J Fungi (Basel) 6:78. https://doi.org/10.3390/jof6020078

7. Alcine Chan MZ, Chua JY, Toh M, Liu SQ (2019) Survival of probiotic strain Lactobacillus paracasei L26 during co-fermentation with $S$. cerevisiae for the development of a novel beer beverage. Food Microbiol 82:541-550. https://doi. org/10.1016/j.fm.2019.04.001

8. Tarrah A, Duarte SV, Castilhos J et al (2019) Probiotic potential and biofilm inhibitory activity of Lactobacillus caseigroup strains isolated from infant feces. J Funct Foods 54:489-497. https://doi. org/10.1016/j.jff.2019.02.004

9. Lemos Junior WJF, Guerra AF, Tarrah A et al (2019) Safety and stability of two potentially probiotic Lactobacillus strains after in vitro gastrointestinal transit. Probiotics Antimicrob Proteins 12:657-666. https://doi.org/10.1007/s12602-019-09565-2

10. Guerra AF, Lemos Junior WJF, Santos GO et al (2018) Lactobacillus paracasei probiotic properties and survivability under stress-induced by processing and storage of ice cream bar or ice-lolly. Ciência Rural 48. https://doi.org/10.1590/0103-8478cr20170601

11. Silva LC, Schmidt GB, Alves LGO et al (2020) Use of probiotic strains to produce beers by axenic or semi-separated co-culture system. Food Bioprod Process 124:408-418. https://doi. org/10.1016/j.fbp.2020.10.001

12. Laureano-Melo R, Caldeira RF, Guerra AF et al (2019) Maternal supplementation with Lactobacillus paracasei DTA 83 alters emotional behavior in swiss mice offspring. PharmaNutrition 8:100148. https://doi.org/10.1016/j.phanu.2019.100148

13. Li J, Hu WZ, Xu YP (2019) Diversity and dynamics of yeasts during vidal blanc icewine fermentation: a strategy of the combination of culture-dependent and high-throughput sequencing approaches. Front Microbiol 10:1588. https://doi. org/10.3389/fmicb.2019.01588

14. ISO 7218 (2007) Microbiology of food and animal feeding stuffs general requirements and guidance for microbiological examinations. Vernier, Geneva. https://www.iso.org/standard/36534.html. Accessed 19 October 2020

15. Cutaia AJ, Reid AJ, Speers RA (2009) Examination of the relationships between original, real and apparent extracts, and 
alcohol in pilot plant and commercially produced beers. J Inst Brew 115:318-327. https://doi.org/10.1002/j.2050-0416.2009. tb00387.x

16. Taverniers I, De Loose M, Van Bockstaele E (2004) Trends in quality in the analytical laboratory, II: analytical method validation and quality assurance. Trac-Trends Anal Chem 23:535552. https://doi.org/10.1016/j.trac.2004.04.001

17. Crawley J, Goodwin FK (1980) Preliminary report of a simple animal behavior model for the anxiolytic effects of benzodiazepines. Pharmacol Biochem Behav 13:167-170. https://doi.org/10.1016/0091-3057(80)90067-2

18. Cryan JF, Mombereau C (2004) In search of a depressed mouse: utility of models for studying depression-related behavior in genetically modified mice. Mol Psychiatry 9:326-357. https:// doi.org/10.1038/sj.mp.4001457

19. Zhang Y, Jia S, Zhang W (2012) Predicting acetic acid content in the final beer using neural networks and support vector machine. J Inst Brew 118:361-367. https://doi.org/10.1002/jib.50

20. Zhao X, Procopio S, Becker T (2015) Flavor impacts of glycerol in the processing of yeast fermented beverages: a review. J Food Sci Technol 52:7588-7598. https://doi.org/10.1007/s13197-015-1977-y

21. Capece A, Romaniello R, Pietrafesa A et al (2018) Use of Saccharomyces cerevisiaevar. boulardii in co-fermentations with $S$. cerevisiae for the production of craft beers with potential healthy value-added. Int J Food Microbiol 284:22-30. https://doi. org/10.1016/j.ijfoodmicro.2018.06.028

22. Mulero-Cerezo J, Briz-Redón Á, Serrano-Aroca Á (2019) Saccharomyces cerevisiae var. boulardii: valuable probiotic starter for craft beer production. Appl Sci 9:3250. https://doi. org/10.3390/app9163250

23. Paula BP, Lago HS, Firmino L et al (2021) Technological features of Saccharomyces cerevisiae var. boulardii for potential probiotic wheat beer development. LWT 135:110233, ahead of print. https://doi.org/10.1016/j.lwt.2020.110233

24. Osburn K, Amaral J, Metcalf SR et al (2018) Primary souring: a novel bacteria-free method for sour beer production. Food Microbiol 70:76-84. https://doi.org/10.1016/j.fm.2017.09.007

25. Peyer LC, Zarnkow M, Jacob F et al (2017) Sour brewing: impact of Lactobacillusamylovorus FST2.11 on technological and quality attributes of acid beers. J Am Soc Brew Chem 75:207-216. https://doi.org/10.1094/ASBCJ-2017-3861-01

26. Mokoena MP (2017) Lactic acid bacteria and their bacteriocins: classification, biosynthesis and applications against uropathogens: a mini-review. Molecules 22:1255. https://doi. org/10.3390/molecules22081255
27. Bintsis T (2018) Lactic acid bacteria as starter cultures: an update in their metabolism and genetics. AIMS Microbiol 4:665-684. https://doi.org/10.3934/microbiol.2018.4.665

28. Gänzle MG (2015) Lactic metabolism revisited: metabolism of lactic acid bacteria in food fermentations and food spoilage. Curr Opin Food Sci 2:106-117. https://doi.org/10.1016/j. cofs.2015.03.001

29. Schurr BC, Hahne H, Kuster B et al (2015) Molecular mechanisms behind the antimicrobial activity of hop iso- $\alpha$-acids in Lactobacillus brevis. Food Microbiol 46:553-563. https://doi. org/10.1016/j.fm.2014.09.017

30. Bourin M, Hascoët M (2003) The mouse light/dark box test. Eur J Pharmacol 463:55-65. https://doi.org/10.1016/S00142999(03)01274-3

31. Can A, Dao DT, Terrillion CE et al (2012) The tail suspension test. J Vis Exp 28:3769. https://doi.org/10.3791/3769

32. Otte C, Gold SM, Penninx BW et al (2016) Major depressive disorder. Nat Rev Dis Prim 2:16065. https://doi.org/10.1038/ nrdp. 2016.65

33. Cheung SG, Goldenthal AR, Uhlemann AC et al (2019) Systematic review of gut microbiota and major depression. Front psychiatry 10:34. https://doi.org/10.3389/fpsyt.2019.00034

34. Winter G, Hart RA, Charlesworth RPG, Sharpley CF (2018) Gut microbiome and depression: what we know and what we need to know. Rev Neurosci 29:629-643. https://doi.org/10.1515/revneuro2017-0072

35. Kim CS, Shin DM (2019) Probiotic food consumption is associated with lower severity and prevalence of depression: a nationwide cross-sectional study. Nutrition 63-64:169-174. https://doi.org/10.1016/j.nut.2019.02.007

36. Du Toit A (2019) The gut microbiome and mental health. Nat Rev Microbiol 17:196. https://doi.org/10.1038/s41579-019-0163-z

37. Kim DH, Cho WI, Lee SJ (2020) Fault tree analysis as a quantitative hazard analysis with a novel method for estimating the fault probability of microbial contamination: a model food case study. Food Control 110:107019. https://doi.org/10.1016/j.foodcont. 2019.107019

38. Tran N, Zhebrak M, Yacoub C et al (2019) The gut-brain relationship: investigating the effect of multispecies probiotics on anxiety in a randomized placebo-controlled trial of healthy young adults. J Affect Disord 252:271-277. https://doi.org/10.1016/j. jad.2019.04.043

Publisher's Note Springer Nature remains neutral with regard to jurisdictional claims in published maps and institutional affiliations. 